\title{
La independencia de los periodistas frente a los regalos e interferencias económicas; una perspectiva comparada entre periodistas y ciudadanía
}

\author{
The independence of journalists from gifts and financial \\ interference; a comparative perspective between journalists and \\ citizens
}

Juan Carlos Suárez Villegas. Universidad de Sevilla. España.

jcsuarez@us.es

$[\mathrm{CV}] \bigcirc \mathrm{C}$

Jesús Díaz del Campo. Universidad Internacional de La Rioja. España.

jesus.diaz@unir.net

$[\mathrm{CV}] \bigcirc \mathrm{C}$

Ruth Rodríguez. Universidad Pompeu Fabra. España.

ruth.rodriguez@upf.edu

$[\mathrm{CV}]$

Agradecimiento: Los resultados de este artículo han sido desarrollados en el marco del Proyecto de Investigación MediaACES. Accountability y culturas periodísticas en España. Impacto y propuesta de buenas prácticas en los medios de comunicación españoles, financiado por el Ministerio de Economía y Competitividad (Mineco/Feder, UE, ref.: CSO2015-66404-P) dentro del Programa Estatal de Fomento de la Investigación Científica y Técnica de Excelencia. https://mediaaccountabilityspain.com

Cómo citar este artículo / Referencia normalizada

Suárez Villegas, J. C., Díaz del Campo, J. y Rodríguez, R. (2021). La independencia de los periodistas frente a los regalos e interferencias económicas; una perspectiva comparada entre periodistas y ciudadanía. Revista Latina de Comunicación Social, 79, 207-222. https://www.doi.org/10.4185/RLCS-2020-1499

\section{RESUMEN}

Dentro del proyecto de I+D+I, "MediaACES. Accountability y Culturas Periodísticas en España. Impacto y propuesta de buenas prácticas en los medios de comunicación españoles", financiado por el Ministerio de Economía y Competitividad de España, se ha llevado a cabo un trabajo de campo entre periodistas y ciudadanos sobre las buenas prácticas periodísticas y los sistemas de rendición de cuenta. Entre las cuestiones formuladas se ha planteado de qué manera los periodistas podría ver comprometida su independencia informativa ante relaciones más o menos estrechas con poderes políticos y económicos, así como cuando puedan mediar regalos que puedan ir desde un simple gesto de cortesía institucional a ciertas formas de compensación por un tratamiento informativo favorable. En esta comunicación se analiza la posición de los profesionales y de los ciudadanos. 
PALABRAS CLAVE: Rendición de cuentas, autorregulación, transparencia, ética periodística, España, regalos.

\begin{abstract}
In a research about "MediaACES.Accountability and Journalistic Cultures in Spain. Impact and proposal of good practices in the Spanish media ", funded by the Ministry of Economy and Competitiveness of Spain, a fieldwork has been carried out between journalists and citizens on good journalistic practices and the accountability system. Among the questions raised has been raised how journalists could be compromised their information independence in more or less close relations with political and economic powers, as well as when they can mediate gifts that can range from a simple gesture of institutional courtesy to certain forms of compensation for a favorable information treatment. In this communication the position of professionals and citizens is analyzed.
\end{abstract}

KEYWORDS: Media accountability systems, journalistic cultures, self-regulation, transparency, journalism ethics, Spain, gifts.

\title{
1. Introducción
}

El objetivo del proyecto de I+D+I "MediaACES. Accountability y Culturas Periodísticas en España. Impacto y propuesta de buenas prácticas en los medios de comunicación españoles" es analizar la ética del periodismo tanto desde un punto de vista autocrítico de los profesionales como desde la perspectiva de expertos de la comunicación y la opinión de la ciudadanía. De este modo se busca triangular estas tres posiciones para verificar su coherencia y eficacia. Es decir, hasta qué punto las buenas prácticas profesionales son así percibidas por la audiencia y se logra una interacción entre ambas partes para una mayor calidad de la información. En el protagonismo de la ética en el ejercicio del periodismo, queda expuesto en diferentes trabajos dentro y fuera de nuestras fronteras, por ejemplo, Aznar, 1999; García Avilés, 2011; Kovach, B.; Rosenstiel, 2001, entre otros.

De manera concreta, en este proyecto se ha intentado abordar tres cuestiones: 1) Una valoración general sobre la ética en el periodismo actual; 2) Los instrumentos para garantizar la ética de los medios; 3) La opinión sobre la ética de los periodistas.

Para llevar a cabo este trabajo se ha realizado una encuesta a periodistas y una serie de focus group con ciudadanos para conocer su opinión sobre el ejercicio de la profesión periodística. Además, se realizó una serie de entrevistas en profundidad a expertos de la ética de la comunicación o representantes profesionales. En este artículo se analiza la opinión de profesionales y ciudadanía sobre cómo los regalos pueden afectar a la independencia del profesional. Tanto la encuesta como los focus group se realizaron en las seis comunidades autónomas participantes en el proyecto: Andalucía, Cataluña, Galicia, El País Vasco, Madrid y Valencia.

\section{Metodología}

\subsection{Encuesta a periodistas}

La encuesta realizada a periodistas consistía en cuestionario conformado por 29 preguntas. Para garantizar la operatividad del mismo, se combinaron preguntas dicotómicas, de opción múltiple y en forma de escala de valoración (Wimmer y Dominick, 2011). El perfil de los periodistas seleccionados para este estudio debía reunir las siguientes características: (1) Trabajar para un medio de comunicación periodística (quedan excluidos de esta manera los profesionales que desempeñen tareas de relaciones públicas); (2) Realizar el ejercicio periodístico (quedan excluidos los 
profesionales que desempeñen tareas técnicas o de organización en la industria de los medios de comunicación); y (3) Tener una ocupación a tiempo completo o principalmente, es decir, ganar el 50 por ciento o más de sus ingresos de su profesión como periodista (los freelance también se incluyen si ganan 50 por ciento o más de sus ingresos con actividades periodísticas).

El cuestionario se administró de forma online a través de la plataforma SurveyMonkey, estando abierta durante tres meses (17 de octubre de 2017 - 17 de enero de 2018). Durante este período temporal, se fueron monitorizando semanalmente las respuestas introducidas. El total de respuestas obtenidas fue de $228(\mathrm{~N}=228) .52 .2 \%(\mathrm{n}=119)$ de los informantes fueron mujeres y un $47.8 \%$ $(\mathrm{n}=109)$ fueron hombres. La mayoría de los informantes $(71.1 \%)$ cuenta con formación universitaria en periodismo. El 53.1\% forma parte de una asociación o colegio profesional de periodistas. Una vez recogido el material, se llevó a cabo el análisis estadístico descriptivo, monovariado y bivariado empleando el software especializado IBM Statistical Package for the Social Sciences (SPSS). Los datos resultantes se triangularon posteriormente con la información cualitativa obtenida de los grupos de discusión con ciudadanos y las entrevistas en profundidad con expertos.

\subsection{Focus group con ciudadanos}

Para llevar a cabo este análisis se ha utilizado la técnica del grupo focal de discusión. El grupo focal consiste en una técnica cualitativa en la que se reúne a un grupo de entre 6 y 8 personas, generalmente desconocidas entre ellas, que debaten sobre un tema concreto bajo la dirección de un moderador/a que introduce preguntas a partir de un guion previamente definido.

El grupo focal es una técnica muy valiosa para obtener material cualitativo, puesto que se generan una serie de interacciones entre las personas que forman el grupo que permiten obtener una información diferente a la que se obtendría de manera individual. En este sentido, los participantes en el grupo son influidos por e influyen en el resto de participantes, interaccionando y compartiendo opiniones y experiencias.

Previamente a la realización de los grupos focales se han planificado los temas que se iban a tratar y se han definido las preguntas para guiar la discusión. Los temas discutidos durante los grupos se han estructurado en tres grandes bloques (ver guion en Anexo I). El primer bloque se ha dedicado a realizar una valoración general sobre la ética en el periodismo actual. El segundo bloque se ha centrado en el análisis de los instrumentos para garantizar la ética de los medios. Y, finalmente, el tercer bloque se ha dedicado a analizar la opinión sobre las actitudes de los periodistas desde un punto de vista ético.

Se llevaron a cabo seis grupos focales, uno en cada una de las siguientes ciudades: Barcelona, Castelló, Madrid, Sevilla, Mondragón y Santiago de Compostela, y han contado con la participación de 38 personas en total, 22 mujeres y 16 hombres. La edad de los y las participantes está equilibrada, con un $42 \%$ situado en edades medias y el resto repartido casi a partes iguales entre los menores de 30 años y los mayores de 60 .

\section{Resultados}

En primer lugar, expondremos los principales resultados obtenidos de las encuestas realizadas a los periodistas españoles, sobre cuáles son los factores que afectan más al ejercicio de la profesión periodística. En concreto, nos centramos en la importancia de las presiones económicas, la formación del periodista y su vinculación con diversas estructuras de organización profesional. Estas 
circunstancias son relevantes para entender el objeto del presente artículo sobre sus actitudes acerca de los regalos y prebendas.

\subsection{Las presiones económicas}

Las presiones económicas son el segundo factor más valorado cuando se pregunta en qué medida afecta a la situación general del periodismo en su comunidad autónoma (7,91 sobre 10). Por su parte, las presiones gubernamentales son puntuadas con un 7,62 y las presiones políticas con un 7,54. La valoración de las presiones económicas como un supuesto dañino para el periodismo se correlaciona con los años de experiencia laboral (con un 99\% de nivel de confianza). De este modo, la valoración del supuesto es mayor entre los periodistas con menos años de experiencia laboral. Asimismo, se puede afirmar, con un $95 \%$ de nivel de confianza, que la edad del informante se correlaciona con la valoración que da a "las presiones económicas". Tanto en este caso como en el de las presiones gubernamentales y políticas hay, en general, una puntuación mayor cuanto más joven es la persona que responde.

Por Comunidades Autónomas, las presiones económicas se consideran el supuesto que más afecta a la situación general del periodismo en Baleares y Canarias (8,33 en ambos casos); mientras, las presiones gubernamentales y las políticas lo son en Galicia (8,78 y 8,51 respectivamente). En cambio, llama la atención el hecho de que en función del tipo del medio en el que trabaja el informante, las presiones económicas son el elemento más valorado entre los profesionales que trabajan en diarios $(8,14$ sobre 10$)$, magazines o revistas $(8,63)$ y radios privadas $(7,92)$. Mientras, las presiones gubernamentales y las políticas son especialmente valoradas entre los periodistas que trabajan en diarios digitales y agencias de noticias, aunque en ninguno de estos dos casos constituyen el supuesto más valorado.

\subsection{Formación del periodista y formas de organización profesional}

En cuanto a la formación, los periodistas en prácticas valoran especialmente la incidencia de las presiones económicas (8,83 sobre 10), mientras que los que cuentan con estudios no homologados dan más importancia a las presiones políticas y gubernamentales ( 9 en cada caso). Por su parte, quienes pertenecen a un sindicato de periodistas otorgan una puntuación ligeramente superior a cada uno de los tres supuestos (presiones económicas, políticas y gubernamentales) que aquellos otros que no son miembros de una organización de este tipo. No ocurre exactamente lo mismo con la pertenencia a una asociación o colegio profesional. Quienes son miembros de este tipo otorgan una mayor puntuación a las presiones gubernamentales y políticas que aquellos otros que no lo son, mientras que en el caso de las presiones económicas ocurre justo lo contrario. Por último, el porcentaje de ingresos que procede de la labor periodística es otra variable que incide en la puntuación otorgada a estos tres supuestos. Aquellos que reciben al menos la mitad del dinero que ganan de su labor periodística le otorgan una puntuación más baja que aquellos cuyos ingresos de su trabajo periodístico suponen menos de la mitad del total.

\subsection{La posición de los profesionales sobre los regalos}

Los periodistas consideran admisible pronunciar conferencias o realizar otras actividades bien remuneradas $(70,2 \%)$; aceptar regalos promocionales tipo merchandising $(64,5 \%)$, viajes pagados para acompañar a la fuente informativa $(50,9 \%)$

No consideran admisible aceptar regalos por valor de más de 200 euros (91,7\%); de entre 30 y 199 $(82,9 \%)$; comidas individuales pagadas por la fuente $(57 \%)$ 
RLCS, Revista Latina de Comunicación Social, 79, 207-222

[Investigación] DOI: 10.4185/RLCS-2020-1499| ISSN 1138-5820| Año 2021

Asimismo, son especialmente tajantes a la hora de rechazar regalos por valor de más de 200 euros $(91,7 \%)$ e incluso aquellos otros regalos por valor de más de 30 y hasta 199 euros $(82,9 \%)$.

Tabla 1. Regalos promocionales (tipo merchandising)

\begin{tabular}{|cc|c|c|c|c|}
\hline & Frecuencia & Porcentaje & Porcentaje válido & $\begin{array}{c}\text { Porcentaje } \\
\text { acumulado }\end{array}$ \\
\hline \multirow{3}{*}{ Válidos } & Sí & 147 & 64.5 & 64.5 & 64.5 \\
& No & 81 & 35.5 & 35.5 & 100.0 \\
& Total & 228 & 100.0 & 100.0 & \\
\hline
\end{tabular}

Tabla 2. Regalos por valor de más de 30 euros y hasta 199 euros

\begin{tabular}{|rl|r|r|r|r|}
\hline & Frecuencia & Porcentaje & Porcentaje válido & $\begin{array}{c}\text { Porcentaje } \\
\text { acumulado }\end{array}$ \\
\hline \multirow{2}{*}{ Válidos } & Sí & 39 & 17.1 & 17.1 & 17.1 \\
& No & 189 & 82.9 & 82.9 & 100.0 \\
& Total & 228 & 100.0 & 100.0 & \\
\hline
\end{tabular}

Tabla 3. Regalos por valor de más de 200 euros

\begin{tabular}{|rl|r|r|r|r|}
\hline & Frecuencia & Porcentaje & Porcentaje válido & $\begin{array}{r}\text { Porcentaje } \\
\text { acumulado }\end{array}$ \\
\hline \multirow{2}{*}{ Válidos } & Sí & 19 & 8.3 & 8.3 & 8.3 \\
& No & 209 & 91.7 & 91.7 & 100.0 \\
& Total & 228 & 100.0 & 100.0 & \\
\hline
\end{tabular}

Tabla 4. Comidas individuales pagadas por la fuente

\begin{tabular}{|rl|r|r|r|r|}
\hline & Frecuencia & Porcentaje & Porcentaje válido & $\begin{array}{c}\text { Porcentaje } \\
\text { acumulado }\end{array}$ \\
\hline \multirow{2}{*}{ Válidos } & Sí & 98 & 43.0 & 43.0 & 43.0 \\
& No & 130 & 57.0 & 57.0 & 100.0 \\
& Total & 228 & 100.0 & 100.0 & \\
\hline
\end{tabular}

Tabla 5. Viajes pagados para acompañar la fuente informativa

\begin{tabular}{|rl|r|r|r|r|}
\hline & Frecuencia & Porcentaje & Porcentaje válido & $\begin{array}{r}\text { Porcentaje } \\
\text { acumulado }\end{array}$ \\
\hline \multirow{2}{*}{ Válidos } & Sí & 116 & 50.9 & 50.9 & 50.9 \\
& No & 112 & 49.1 & 49.1 & 100.0 \\
& Total & 228 & 100.0 & 100.0 & \\
\hline
\end{tabular}

Tabla 6. Pronunciar conferencias o realizar otras actividades bien remuneradas

\begin{tabular}{|rl|r|r|r|r|}
\hline & Frecuencia & Porcentaje & Porcentaje válido & $\begin{array}{c}\text { Porcentaje } \\
\text { acumulado }\end{array}$ \\
\hline \multirow{2}{*}{ Válidos } & Sí & 160 & 70.2 & 70.2 & 70.2 \\
& No & 68 & 29.8 & 29.8 & 100.0 \\
& Total & 228 & 100.0 & 100.0 & \\
\hline
\end{tabular}




\subsection{La actitud de la ciudadanía ante regalos y prebendas}

En este apartado, se recoge la percepción de la ciudadanía sobre algunos de los supuestos relevantes que podrían ser susceptibles de afectar la independencia del periodista. Realizamos una breve presentación de las diferentes situaciones planteadas, en las que se recogerá las respuestas más significativas dadas en cada una de ellas.

Para muchos, los regalos y prebendas aceptables o no depende de la intencionalidad del emisor. Los regalos no deberían condicionar la noticia a futuro, deberían permitir trabajar al o a la periodista con libertad.

Depende si el regalo es antes de que hablen, o sea yo voy a darle algo a este periodista para que hable bien de mí o si se lo das a posteriori como premio, o a lo mejor porque te apetece y ya está, porque se lo das a cualquier periodista que te haya invitado. O sea, hay diferencias en las intenciones, pero cada uno aceptará lo que quiera. (HABLAN)(GD01-M)

Regalos no se deberían aceptar en ningún caso, según algunas de las personas de los grupos de discusión. Los regalos son sobornos y siempre están acompañados de alguna intención. Alguien comenta que esta práctica es más habitual en España porque culturalmente ha sido más propensa a recibir regalos a cambio de influencia.

Que le puede ir mejor o peor a la empresa según lo que yo diga. Pero hay muchas formas de

hacer regalos en el periodismo político: una colaboración con un medio público o que el político hable a tu jefe bien de ti o mal, que te den más facilidades o menos.(GD03-H)

Algunos establecen la línea divisoria entre lo que es ético y lo que no en la cantidad, la relevancia o el precio del regalo.

[El límite está] Pues en el valor del regalo.(GD05-M)

Para otros depende del o de la periodista, que es quien sabe si realmente ese regalo puede ejercer una influencia en su trabajo o no, o si acepta ese condicionamiento.

Yo creo que si es una entrada de futbol un día, el otro, el siguiente y el siguiente también, y

después un viaje en un crucero, esto ya pasa. Una entrada en el futbol es condicionar, bueno, depende del periodista, si quiere ser condicionado eso también... (GD05-H)

El regalo es un símbolo de algo que puede intervenir en la objetividad del periodista, pero no es el único ni el más peligroso en términos de influencia.

De todas formas, en la actualidad existe más transparencia sobre este tipo de prebendas y regalos. Por ello el o la política utilizan menos este recurso como modo de influencia en el o la periodista. Antes era una práctica mucho más común. 


\subsection{Regalos promocionales (tipo merchandising)}

Este tipo de regalos puede darse de manera sistemática a toda persona que tome contacto con la empresa que los realiza, por tanto no tiene por qué estar asociado a una intención de influenciar la noticia o la opinión de los o las periodistas.

Pero de otras formas tengo que decirte que si vas a un sitio tú como periodista, tú como medio, tú como compañía y se da a todo el mundo el detalle, eso no tiene nada que ver...

(GD02-M)

Si los regalos provienen de las empresas sobre las cuales tiene que opinar el o la periodista, no sería ético recibirlos. Esto es frecuente en el ámbito de la tecnología, en el cual además los regalos son de valor económico considerable y puede condicionar el trabajo periodístico.

\subsection{Regalos según el valor económico que tengan}

En este punto no hay un acuerdo generalizado. Se insiste en que aceptar o no el regalo depende de la intencionalidad y la capacidad para influenciar a aquella persona a la que se les regala. Para algunos cualquier regalo es un intento de influenciar, por tanto no debe aceptarse ni aunque sea por un euro. En el caso opuesto, se plantea un regalo valioso económicamente pero que no tiene capacidad de influencia ya que el periodista ya está posicionado del lado del emisor del regalo. En ese caso ese regalo tampoco jugaría un papel específico en influenciar la noticia.

\subsection{Entradas, pases o servicios gratuitos}

En este punto se realiza una diferencia entre aquellos/as periodistas que van al espectáculo para trabajar y aquellos/as que reciben entradas como regalos para utilizarlos en su tiempo libre. Por ejemplo, pagar la entrada a personas que luego harán una crítica de un espectáculo es simplemente facilitar que se hable del espectáculo pero no condiciona el carácter negativo o positivo de la crítica posterior.

Esto en los periodistas es habitual y además yo creo que está bien, evidentemente el

periodista va a cubrir una información, por lo menos que pueda entrar gratuitamente.(GD03-

H)

Si es un periodista que se dedica a hacer crítica de cine solamente faltaría...(GD02-M)

Un caso singular es el de las entradas deportivas. Los palcos se consideran un espacio de influencia. En este caso también se desaprueban los regalos de entradas, en general.

O tiene que hacer una información sobre los préstamos que debe todavía el Atlético de

Madrid y que no sabe cómo lo va a pagar, a la hora de escribir seguro que va a estar condicionado, segurísimo que sí.(GD03-H) 
Otras personas ponen el acento en quién recibe las entradas, si la persona que realizará la noticia o su familia y amigos/as. En este último caso se entiende más como un regalo y se desaprueba.

Pero que tenga entradas para toda su familia o por ejemplo, que yo a mí que me gusta Rafael, que mi hermano sea periodista y me diera entrada de la primera fila... hombre pues a mí me gustaría la verdad pero reconozco...(GD02-M)

Los regalos a la persona, desvinculados en principio del trabajo realizado, se consideran un regalo personal que se puede intercambiar por un favor personal.

Claro, un favor personal, ¿no? (GD04-M)

\subsection{Comidas individuales pagadas por la fuente}

Las comidas con las fuentes conviene que no sean individuales, ello podría condicionar al o a la periodista que va a hacer la noticia.

Individuales no, pero colectivas sí que se hacen, por ejemplo en navidad los partidos, no todos, lo que hacen es que hacen una cena de navidad e invitan a todos los medios, y si se invita a todos los medios pues bueno no sé, a lo mejor...(GD02-H)

Las comidas individuales pueden ser legítimas pero el límite de lo considerado ético o no es en algunos casos difícil de definir. El valor económico de las comidas podría ser un parámetro para medirlo, pero un encuentro más personal con un político deja el límite un poco más difuso y puede ser cuestionable.

Pues yo creo que es admisible que un cronista parlamentario o un periodista político tenga una jornada en no sé dónde con el político de turno para que conozca más en profundidad a ese político, o conozca otras facetas, o se vayan a comer. Eso sí que me parece admisible, ahora, la raya que marca lo admisible de lo no admisible quizá esté un poco difusa y sea muy peligrosa.(GD03-H)

\subsection{Viajes pagados para acompañar la fuente informativa}

Algunas/os periodistas deben viajar para encontrar la noticia. En este sentido, la falta de acuerdo escriba en quién debería pagar los viajes: ¿la fuente, el medio, el propio periodista? El cuestionamiento ético se hace porque el pago por la fuente pudiera condicionar la noticia. 
Entradas y viajes pagados para ir a la fuente informativa, esto yo creo que no se considerarían regalos ya que son herramientas que el periodista necesita para desarrollar su trabajo, o sea no le estás premiando al periodista sino que le estás permitiendo hacer su trabajo.(GD01-M)

Este hecho puede hacerse mucho más evidente cuando se acompaña a una figura política de manera habitual en sus viajes profesionales para generar noticias.

Me parece que es una prostitución de la información porque se va a ver tendenciosamente influenciada.(GD03-H)

Depende de las condiciones en las que se viaje. Algunos destacan la importancia de la cantidad del gasto: si supone un derroche innecesario, no es ético.

Me parece fatal y nadie lo ha criticado hasta que ha llegado la crisis.(GD03-H)

\subsection{Pronunciar conferencias o realizar otras actividades bien remuneradas}

La lógica del pago en conferencias u otras actividades entre los periodistas es similar que en el caso de entradas o viajes. En general, se considera que estas actividades son propias del ejercicio del profesional, y por tanto deben estar remuneradas. Que sean bien pagadas o no, depende en todo caso del prestigio del o de la profesional, por tanto no es cuestionable éticamente.

Pero te están pagando como persona cualificada, porque si esa persona cree que le pagan

demasiado poco pues te dirá: tú me quieres a mí en una conferencia porque soy alguien relevante en este tema, y si no estás dispuesto a pagarme ese dinero pues coge a cualquiera que te encuentres por la calle que es una persona que su opinión no cuenta.(GD01-M)

Otras veces las mismas conferencias o actividades extras pueden ser beneficios en pago de favores: las conferencias se "consiguen" por parte de alguien que tenga poder para ofrecerlas a periodistas. Este hecho supone sacar provecho del poder como periodista, y es reprobable.

Yo sí que lo veo grave, evidentemente. Una manipulación y una tergiversación de las actividades propias de los periodistas, que no deben de dejarse comprar, vamos, para mí lo veo como una compra.(GD03-H)

Aceptar asistir a conferencias u otras actividades también puede ser una concesión del o de la profesional por la relación estrecha con algún partido político, no necesariamente de su ideología. Se plantea más bien como un estado de ayuda mutua en el que las dos partes necesitan hacer concesiones para mantener esa relación. Es el caso de los o las periodistas a las que se les adscribe el seguimiento de un determinado partido político. 
Sí, pero en el momento que haces seguimiento de un partido, te guste o no tienes una relación de relaciones públicas total con los equipos de ese partido, y ellos te dan y tú tienes que ceder y esa es la relación para no caer en exceso ninguna de las dos partes, entonces te lo plantearías como..., no digo que fuera, pero te lo planteabas de otra vista.(GD03-H)

Algunas personas cuestionan que los periodistas de renombre, con una sólida credibilidad, acepten hacer publicidad.

Yo tengo un poco de dudas sobre si es ético que los periodistas, sobre todo aquellos que tienen una imagen pública, que se les conoce por la televisión o los medios, hagan publicidad de otros productos; esto no me gusta mucho porque parece que profesionales a algunas personas les pueden parecer como un referente de verdad y entonces si yo te digo agua Ribes es buenísima pues igual me crees porque te fías de mí. ... (GD01-M)

Por esta razón, para algunos de los participantes entienden que los códigos éticos deberían incluir un apartado sobre estas cuestiones.

Quiero decir que cada casa es un mundo, no se puede generalizar, por eso la asociación de periodistas tendría que hacer un libro ético, que aquí hablamos de él, y especificar cuando son los casos, lo mismo que los regalos, pues claro, es que hay regalos que son cortesía que no tienen valor ninguno. (GD06-H)

\section{Discusión}

El periodista no sólo debe ser honesto e independiente, sino que también debe parecerlo, pues su función pública podría generar dudas si se muestra propenso a ser agasajado con regalos por una de las partes. La honorabilidad de una posición pública, y la del periodista lo es, aunque lo haga por cuenta propia, debe invitar a la mesura en su relación con las diferentes partes que forman parte de su labor profesional.

A este respecto, el periodista ha de tener en cuenta circunstancias como si el regalo guarda relación con la actividad de promoción de la empresa o si solo le hace a él en exclusiva, lo que puede suponer una señal de marcar un trato preferencial con la expectativa de que sea correspondido. Además, esta receptividad al regalo puede generar desconfianza por parte del público en su independencia profesional. La confianza tiene también una dimensión pública.

Por parte de los ciudadanos encontramos una panoplia de opciones muy amplia. Desde quienes consideran que los regalos no se deberían aceptar nunca, a quienes estiman que los regalos pueden razonables si adquieren más un sentido simbólico que económico. No es lo mismo regalar un llavero 
o una botella de vino, de un valor discreto, a regalos muy distinguidos con un alto coste económico. Para algunos ciudadanos, en la cultura mediterránea, tan habituada a granjearse beneficios a través de favores, los regalos tienen siempre una intención. Y seguramente, aunque comiencen con pequeños detalles, seguramente se tenderá a deslizarse por una pendiente resbaladiza de prebendas con las que influir en la labor del periodista. Dicho de otra forma, son formas sutiles de sobornos, en los que se compra un cierto "derecho" de facto a poder influir.

Como regalo no hay que entender simplemente un objeto material, puede ser también actividades excepcionales cuyo valor económico también es significativo: comida en ciertos restaurantes, viajes, entradas a espectáculos o actividades de ocios. No se trata de vivir en una burbuja. Los periodistas también tienen sus afinidades personales y pueden cultivar relaciones afectivas, dentro de las cuales puede generarse expresiones mutuas de sociabilidad o amistad, como la invitación a una comida o un determinado regalo razonable económicamente. Pero el periodista deberá recelar de aquellos otros regalos desproporcionados o exclusivos que puedan ser interpretados como un gesto de proximidad que pueda condicionar su independencia profesional.

Un gesto de cordialidad social no debe ser confundido ni correspondido con un trato de favor. Por eso, parece especialmente relevante no aceptar regalos provienen de las empresas sobre las cuales tiene que opinar el o la periodista, no sería ético recibir regalos. Esto es frecuente en el ámbito de la tecnología, en el cual además los regalos son de un valor económico considerable y puede condicionar en gran medida el trabajo periodístico. Por otro lado, consideran que "pronunciar conferencias o realizar otras actividades bien remuneradas a los periodistas puede ser también un arma de doble filo. Pueden ser razonables cuando se trata de emolumentos proporcionales al prestigio del conferenciante y no como un complemento extra y reiterado que pueda generar deuda con quienes promueven dichas conferencias". Algunos consideran que algunos pagos son exorbitados y pueden implicar la retribución de favores o cuestiones no relacionadas específicamente con aquello que se remunera. Otros, que estos pagos deberían estar regulados y no dejarse la remuneración a los precios del mercado.

Otro supuesto planteado es que periodistas de renombre protagonicen anuncios publicitarios. A su juicio, esta doble actividad es contraria al código deontológico, porque utiliza su prestigio profesional al servicio de la marca publicitada, lo que puede confundir al público que le asocia con su credibilidad informativa. Por otra lado, el hecho de que periodistas con dicho caché profesional opten por prestar sus servicios a la publicidad como si fuera una estrella mediática no da buena imagen. Hay que distinguir la información de la publicidad y, por tanto, convendría deslindar el ejercicio simultáneo de ambas actividades. A este respecto hay un interesante informe de la Comisión de Arbitraje, Quejas y Deontología de la FAPE, que distingue entre el rendimiento de la popularidad mediática del periodista y su actividad profesional. No serían admisibles publicidad que se puedan confundir con la actualidad informativa, pero sería excesivo vedarle su participación en otros contextos del mercado. No es lo mismo anunciar unas sopas que un producto financiero. En resumen de la ponencia dice lo siguientes:

La Comisión de Arbitraje, Quejas y Deontología de la Federación de Asociaciones de

Periodistas de España (FAPE) considera que el periodismo cumple una función constitucional

que no debe quedar comprometida por prácticas poco sensibles con sus valores de independencia y honestidad informativa. A este respecto, la participación de periodistas en formatos que puedan prestarse a confusión sobre su función social y que debiliten la 
RLCS, Revista Latina de Comunicación Social, 79, 207-222

[Investigación] DOI: 10.4185/RLCS-2020-1499| ISSN 1138-5820| Año 2021

credibilidad de la profesión no resulta aceptable. En cambio, esta posición no presupone que

la participación puntual de periodistas en spots publicitarios suponga per se una falta deontológica, siempre que se delimite de manera adecuada tanto por su contexto como por su contenido que no guarda relación con su función informativa (Resolución 2014/93). Sobre el resultado de la actividad de la Comisión se han publicado recientes trabajos como SuárezVillegas, 2015a; Serrano-Moreno, 2015.

Los periodistas reconocen que la finalidad de los obsequios es predisponer positivamente al comunicador hacia el emisor de esos regalos o la entidad a la que representa, y por ello apuntan que resulta difícil que no condicionen el contenido de la noticia. A partir de esta reflexión, responden de forma mayoritaria que, ante determinados regalos y beneficios que puedan ofertarle otras empresas, instituciones o particulares, se debe actuar con honestidad y sentido común, pues "no hay nadie que no haya aceptado un detalle de empresas o instituciones." Asimismo, afirman que no hay motivos para rechazar regalos de pequeño valor, ya que en muchos casos se reciben como agradecimiento y resultaría desagradable su no aceptación. Por ejemplo, los artículos de merchandising con un valor muy limitado, como publicidad de la empresa no tendrían por qué tener ningún efecto sobre los comunicadores. Estos son los regalos que la profesión acepta sin que se considere comprometida su independencia.

Sí parece existir una opinión consensuada de recelar de regalos de un valor significativo sin admitir que puede haber una intención clara del donante por influir en la noticia. Por eso, hay que diferenciar entre la aceptación de regalos simbólicos (entradas y pases gratuitos, por ejemplo) y aquellos otros que implican una forma de ser agasajado por una empresa, entidad o institución sobre la cual informa el periodista en su medio, sobre todo si se superan un determinado valor.

Los códigos deontológicos son tajantes a la hora de establecer el rechazo de cualquier obsequio, por nimio que sea su valor. En este sentido, se cita el ejemplo del diario El País que acostumbra a devolver todos los obsequios que llegan a su empresa. En el caso del libro de estilo de Canal Sur Televisión, se plantea una actitud más lasa, dado que afirma lo siguiente: "Tampoco se admitirán regalos de fuentes informativas, salvo que se trate de muestras de cortesía socialmente asumibles". En este mismo sentido, el Libro de Estilo de El Mundo advierte del riesgo de la fuente resbaladiza que constituye la posibilidad de aceptar regalos que puedan hipotecar la independencia del informador. Por eso, conviene estar atento a que la naturaleza del regalo no vaya más allá de una mera cortesía y se convierta en una forma de pago en especie por las expectativas que se despiertan para recibir un trato de favor. También es distinto en el que se produzca el regalo, si antes de que aparezca una noticia, que podría claramente buscar que el periodista se haga eco con mayor atención de la fuente donante, o después de la noticia, en la que se trata de un detalle de agradecimiento por un trabajo bien hecho. No hemos de ignorar, que la introducción de las nuevas tecnologías ha contribuido a una cultura de mayor vulnerabilidad del trabajo periodístico, lo que puede favorecer que algunos profesionales se sientan más predispuestos a considerar su labor más comunicativa que informativa y en este sentido actuar como correa de transmisión de intereses comerciales, en una simbiosis no declarada de colaboración mutua (Suárez-Villegas, 2015b). 
En resumen, los regalos no deben lograr nunca silenciar una noticia, o suavizar versiones de los hechos para favorecer a una de las partes. También existe por parte de la mayoría de los profesionales una tendencia a rechazar la participación de periodistas prestigiosos en actividades publicitarias. Estiman que esto condiciona su imagen de independencia y confunde al público. A este respecto, una resolución informe de FAPE, advierte de este peligro, pero entiende que no debe ser llevado al extremo de considerar que la audiencia no distingue los contextos en los que aparece los periodistas. En este sentido, dada la servidumbre de su imagen por aparecer en televisión, puede ser razonable también un cierto uso de su popularidad en otros contextos, siempre que no se vincule con parcelas sensibles como las actividades económicas o asuntos de actualidad. Pero esto nada tendría que ver con la aparición del periodista en otras situaciones como puede ser la publicidad de un vino o un tipo de alimento. No es su parte profesional la que estaría rentabilizando, sino su popularidad en la villa televisiva.

\section{Conclusiones}

Los profesionales del periodismo consideran que las presiones de todo tipo son uno de los principales problemas que sufre el periodismo hoy en día, sobre todo las de tipo económico, por encima de las gubernamentales o políticas. No obstante, factores como el tipo de medio, la formación previa, la pertenencia a un sindicato, asociación o colegio profesional, y el volumen de ingresos influyen en esta percepción. Asimismo, la posición ante la posible aceptación de regalos o prebendas difiere en función de su naturaleza. En general, se considera admisible el pronunciar conferencias o aceptar regalos promocionales de merchandising, mientras que se rechaza de forma tajante el aceptar otro tipo de regalos o comidas individuales pagadas por la fuente.

En general, la mayoría de los ciudadanos consideran los regalos y prebendas aceptables o no depende de la intencionalidad del emisor. El periodista debe valorar si con dicho regalo se pretende condicionar su imparcialidad informativa, pues no se debe confundir ciertas formas de cortesía con favores o prebendas que generen un sentimiento de deuda. Algunos ciudadanos advierten de la posibilidad de que se trata de un "regalo-trampa", formas sutiles de genera una confianza interesada para acceder con más facilidad al periodista y lograr así cierto trato de favor. Entre otras, estas son las principales opiniones de los ciudadanos respecto a los obsequios y los principales problemas que suponen:

- Para muchos, los regalos y prebendas aceptables o no depende de la intencionalidad del emisor. Los regalos no deberían condicionar la noticia a futuro, deberían permitir trabajar al o a la periodista con libertad.

- Regalos no se deberían aceptar en ningún caso, según algunas de las personas de los grupos de discusión. Los regalos son sobornos y siempre están acompañados de alguna intención.

- De todas formas, en la actualidad existe más transparencia sobre este tipo de prebendas y regalos. Por ello el o la política utilizan menos este recurso como modo de influencia en el o la periodista. Antes era una práctica mucho más común.

- Pagar la entrada a personas que luego harán una crítica de un espectáculo es simplemente facilitar que se hable del espectáculo pero no condiciona el carácter negativo o positivo de la crítica posterior.

- Los palcos se consideran un espacio de influencia. En este caso también se desaprueban los regalos de entradas, en general.

- Las comidas individuales pueden ser legítimas pero el límite de lo considerado ético o no es en algunos casos difícil de definir. Las comidas con las fuentes conviene que no sean individuales, ello podría condicionar al o a la periodista que va a hacer la noticia. 
- Algunas/os periodistas deben viajar para encontrar la noticia. En este sentido, la falta de acuerdo en el debate escriba en quién debería pagar el coste de los viajes. Algunos destacan la importancia de la cantidad del gasto: si supone un derroche innecesario, no es ético.

- Se considera que pronunciar conferencias o realizar actividades extras son propias del ejercicio del o de la profesional, y por tanto deben estar remuneradas. Que sean bien pagadas o no, depende en todo caso del prestigio del o de la profesional, por tanto no es cuestionable éticamente. Algunos consideran que algunos pagos son exorbitados y pueden implicar la retribución de favores o cuestiones no relacionadas específicamente con aquello que se remunera.

\section{Bibliografía}

Alsius, S. (ed) (2010): The Ethical Values of Journalists. Field research among media profesionals in Catalonia. Barcelona: Lexikon.

Alsius, S.; Salgado, F. (ed) (2010): La ética informativa vista por los ciudadanos. Contraste de opiniones entre los periodistas y el público. Barcelona: UOC.

Aznar, H. (1999): Ética y periodismo. Barcelona: Paidós.

Bertrand, C. J. (2000): Media Ethics and Accountability Systems. Londres: New Brunswick.

Christians, C.; Traber, M. (eds.) (1997): Communication Ethics and Universal Values. California, 1997

Comisión de Arbitraje, Quejas y Deontología de la FAPE. Informe / Resolución 2014/93, "Sobre vulneración del deber del periodista de no simultanear actividades periodísticas con su aparición en anuncios publicitarios". http://www.comisiondequejas.com/wpcontent/uploads/2015/09/93.pdf

Fengler, S.; Eberwein, T.; Mazzoleni, G.; Porlezza, C.; Russ-Mohl, S. (2014): Journalists and media accountability. An international study of news people in the digital age. Nueva York: Peter Lang Publishing.

González-Esteban, J.-L., García-Avilés, J.-A., Karmasin, M. y Kaltenbrunner, A. (2011): "La autorregulación profesional ante los nuevos retos periodísticos: estudio comparativo europeo", en Revista Latina de Comunicación Social, $66.426 \quad-453$ http://www.revistalatinacs.org/11/art/940_Elche/19_Esteban.html

Frost, C. (2011). Journalism ethics and regulation. 3a ed. Londres: Longman.

Kovach, B.; Rosenstiel, T. (2001): The elements of journalism: What newspeople should know and the public should expect. Nueva York: Three Rivers.

Lambeth, E. (1992): Periodismo comprometido. Un código de ética para la profesión. México: Limusa. 
RLCS, Revista Latina de Comunicación Social, 79, 207-222

[Investigación] DOI: 10.4185/RLCS-2020-1499| ISSN 1138-5820| Año 2021

Romero-Domínguez, L. y Suárez-Villegas, J.C., La actitud ética de los periodistas españoles frente a los conflictos de intereses. International Journal of Iberian Studies, Volume 25, Number 2, 7 November 2012,pp. 95-110(16) https://doi.org/10.1386/ijis.25.2.95_1

Salgado, F. (2010), Los obsequios inocuos: que se le puede regalar a un periodista sin comprometer su independencia, en Salvador Alsius y Francesc Salgado (eds.) La ética informativa vista por los ciudadanos. Contraste de opiniones entre los periodistas y el público, UOC. pp. 165-180.

Serrano Moreno, J. (2015), Ética del Periodismo Español. Las 100 primeras Resoluciones de la Comisión de Arbitraje, Quejas y Deontología de la FAPE. Editorial Fragua, Madrid.

Suárez-Villegas, J.C. (2015a). La Comisión de Deontología como referente de la autorregulación del periodismo: apuntes doctrinales sobre el periodismo digital (Self-regulation of offline and online journalism in Spain in the experience of the Arbitration, Complaints and Ethics Commission"), Vol. 28(3), pp. 135-149. Communication \& Society ISSN 0214-0039 E ISSN 2386-7876 https://doi.org/10.15581/003.28.3.135-149 www.communication-society.com

Suárez-Villegas, J.C. (2015b). Nuevas tecnologías y deontología periodística: comparación entre medios tradicionales y nativos digitales. El profesional de la información, v. 24, n. 4, pp. 390-395. http://dx.doi.org/10.3145/epi.2015.jul.05

Wimmer, R. D.; Dominick, J. R. (2011). Mass media research: an introduction (novena edición). Canadá: Wadsworth, Cengage Learning.

\section{AUTORES:}

\section{Juan Carlos Suárez Villegas.}

Profesor Titular de la Universidad de Sevilla acreditado a Catedrático en Periodismo. Sus principales líneas de investigación se han centrado en la ética y deontología de la comunicación, con más de diez libros y más de una treintena de artículos científicos y aportaciones a congresos internacionales. Entre sus trabajo, cabría destacar Principios de Ética Profesional. A propósito de la actividad informativa (Tecnos, 2001); La maternidad masculina. Y otros ensayos sobre la igualdad entre mujeres y hombres desde otro punto de vista (Dykinson, 2012), traducido éste al inglés y al italiano. Investigador principal de los proyectos de I+D+I sobre ética periodística: "La expectativa de la ciudadanía andaluza frente a la ética de los medios de comunicación" (2006-2010); "desafíos éticos del periodismo digital. Un análisis comparativo entre cinco países europeos" (2012-2015). Actualmente, investigador en el proyecto de la Universidad Pompeu Fabra sobre "Accountability y Culturas Periodísticas en España. Impacto y propuesta de buenas prácticas en los medios de comunicación españoles".

Responsable del Grupo de Investigación del Plan Andaluz de Investigación, Desarrollo e Innovación (PAIDI) SEJ-495: "Pensamiento Crítico, Comunicación y Derechos Humanos". Evaluador de la Agencias Nacionales de Evaluación y Prospectiva (ANEP) y de la Agencia de la Calidad Universitaria italiana (ANVUR). Ha realizado estancia de investigación en las Universidades de Oxford (1991), Bolonia (1992), La Sapienza (2009 y 2013) y Berkeley (2015). Para esta última obtuvo una beca de la Universidad de Sevilla dentro del programa de Excelencia TECH. Miembro de la Comisión de Arbitraje, Quejas y Deontología del Periodismo de España, Profesor visitante en la Universidad Autónoma del Estado de Méjico y Universidad Anáhuac.

jcsuarez@us.es

Orcid ID: http://orcid.org/0000-0002-2199-7028

Google Scholar: https://scholar.google.es/citations?user=2zCN-zIAAAAJ\&hl=es 


\section{Jesús Díaz-Campo}

Profesor Titular de Comunicación, director de Investigación y secretario del Comité de Ética de la Investigación de la Universidad Internacional de La Rioja. España. Doctor en Periodismo por la Universidad Complutense de Madrid. Obtuvo una Beca de Formación del Profesorado del Ministerio de Educación y Cultura. Está acreditado por ANECA como Profesor Titular y cuenta con un sexenio de investigación reconocido por la CNEAI. Sus principales líneas de investigación se centran en la ética de la comunicación y la responsabilidad social corporativa, el periodismo digital, la comunicación política y la radio. Ha publicado unos 50 artículos sobre estas materias. En la actualidad es director del Grupo de Investigación "Comunicación y Sociedad Digital" (COYSODI), investigador principal del Proyecto "Consumo de noticias en medios sociales. Análisis de factores en la selección y difusión de contenidos mediáticos", (MINECO/FEDER, UE, referencia CSO201786312-R) y forma parte del proyecto y Accountability y Culturas Periodísticas en España. (MINECO/FEDER, UE, referencia CSO2015-66404-P). 15 años de experiencia profesional como periodista y profesional de la comunicación.

jesus.diaz@unir.net

Orcid ID: http://orcid.org/0000-0001-5014-8749

Google Scholar: http://scholar.google.es/citations?user=rNxx5WYAAAAJ\&hl=es

\section{Ruth Rodríguez-Martínez}

Ruth Rodríguez-Martínez es doctora en Periodismo por la Universidad Complutense de Madrid. Es profesora de Periodismo en el Departamento de Comunicación de la UPF y es miembro del Grup de Recerca en Periodisme de la UPF. Sus principales líneas de investigación son el periodismo cultural, la ética en los medios y el periodismo digital. Ha participado en diversos proyectos de investigación financiados por el Ministerio y la Comisión Europea. Es investigadora principal del Proyecto de Investigación MediaACES. Accountability y Culturas Periodísticas en España. Impacto y propuesta de buenas prácticas en los medios de comunicación españoles (MINECO/FEDER, UE, ref: CSO2015-66404-P).

ruth.rodriguez@upf.edu

Orcid ID: http://orcid.org/0000-0001-5633-6126 